\title{
An Evaluation of Gaming-Related Harms in Relation to Gaming Disorder and Loot Box Involvement
}

\author{
Patrick Andrew Kerin Carey ${ }^{1} \cdot$ Paul Delfabbro $^{1}$ (D) Daniel King ${ }^{2}$
}

Accepted: 24 May 2021 / Published online: 7 June 2021

(C) The Author(s), under exclusive licence to Springer Science+Business Media, LLC, part of Springer Nature 2021

\begin{abstract}
The specific nature of harm and functional impairment in the context of gaming disorder (GD) has received limited attention. In this study, we present one of the first concerted attempts to measure the types and degree of harm experienced by people displaying signs of problem gaming. Attempts were made to assess the extent to which types of harm were attributable to gaming as opposed to other factors. The study also investigated potential behavioural indicators of harmful involvement, including exposure to loot boxes. A sample of 471 regular gamers $(M=380, F=73)$, recruited through the online platform Prolific, completed a survey where problem gaming was identified using Petry et al.'s (2014) checklist. Individuals who met the cut-off for gaming disorder scored higher than the non-problem group on most dimensions of harm, with physical and psychological types being the most common issues. Loot box expenditure was low $(M=\$ 25$ in 3 months, for the $10.8 \%$ of respondents who played loot boxes) but significantly positively associated with the degree of gaming-related financial harm. This study shows that problem gaming is most strongly associated with physical or psychological harm and that financial harms may manifest in gaming activities that facilitate continuous spending options.
\end{abstract}

Keywords Gaming · Harm · Loot boxes · Gambling · Internet gaming disorder

In 2013, Internet gaming disorder (IGD) was recognized in the DSM-5 as a condition warranting further study (American Psychiatric Association, 2013) and has now been included in the International Classification of Disorders or ICD-11 (ICD, 2019). The IGD criteria refer to the conventional symptoms of an addictive disorder, including impaired control; tolerance and withdrawal; continued engagement in gaming despite harm; and functional impairment due to gaming. IGD has been found to be associated with comorbid problems, including

Paul Delfabbro

paul.delfabbro@adelaide.edu.au

1 School of Psychology, University of Adelaide, Adelaide, Australia

2 College of Education, Psychology and Social Work, Flinders University, Adelaide, Australia 
depression and anxiety (Cheng et al., 2018; Gonález-Bueso et al., 2018; Kim et al., 2016; Wu et al., 2015); poor diet and general health (King \& Delfabbro, 2019a, b; Tetik et al., 2018); and poorer sleep, including sleep disorders (Männikkö et al., 2015; Satghare et al., 2016). Other correlates identified have included a heightened risk of other addictive issues (Burleigh et al., 2019; Spekman et al., 2013); social problems, including relational conflict and loss (King \& Delfabbro, 2019a; Northrup \& Shumway, 2014); and disruption to study and work (Wölfling et al., 2019).

Despite these convergent findings, the validity of gaming disorder as a behavioural addiction has been questioned. Przybylski et al. (2016), for example, have drawn attention to the low prevalence rates ( 0.3 to $1.0 \%$ in the general population) when assessed in more methodologically robust studies or using more stringent criteria, whereas others have argued that the condition may only be a set of maladaptive behaviours associated with an underlying mood disorder (Kardefelt-Winther, 2014; Wood, 2007). Similarly, a meta-analysis by Stevens et al. (2020) reported that the worldwide prevalence of GD was $3.05 \%$, but this figure reduced to $1.96 \%$ when excluding studies based on more stringent sampling criteria. For excessive gaming to be considered a genuine clinical condition, it is important to show that the behaviour gives rise to genuine harm and that this can be attributed to the activity itself (i.e. burden of disease) (King \& Delfabbro, 2018a).

\section{Harm in Behavioural Disorders}

Such research has, for example, been undertaken in the related field of gambling studies, in which a number of studies have shown that problem gambling can be distinguished from lower risk gambling on a range of harm dimensions (e.g. Browne et al., 2016; Browne \& Rockloff, 2018; Delfabbro, Georgiou, \& King, 2020a; Rawat et al., 2018). Browne et al. (2016) showed that problem gamblers score significantly higher on measures of financial harm (e.g. reports of significant financial distress) and report greater psychological distress; declines in physical health; disruption to social relationships; and difficulties in work or study. So far, no systematic measurement of harm has been undertaken for gaming to determine whether individuals who meet the IGD criteria on screening measures differ significantly from other gamers using an extensive range of harm measures. Instead, as shown above, current understanding of the impacts of gaming have been based on a more piecemeal approach that combines separate selfreport measures and assumes a degree of causality (e.g. between IGD symptoms and depression). Therefore, it is usually not possible to examine which categories of harm tend to differentiate problem gamers from the general gamer population.

\section{Digital Convergence: Gambling and Gaming}

A further reason for interest in harm is that an increasing body of research shows that gaming may be becoming more similar to gambling through a gradual process of convergence (Delfabbro \& King, 2020; Gainsbury, 2019; King et al., 2010; Macey \& Hamari, 2019), with excessive gambling a behaviour shown to cause significant harm (Browne et al., 2016). Gambling-like features, including those that allow for greater financial expenditure, are increasingly included in gaming (King et al., 2019; King \& Delfabbro, 2020; McCaffrey, 2019). Such features raise the possibility that excessive gaming may not only contribute to 
harm through high levels of involvement (e.g. 30+ hours of play per week), but also because it is more expensive and can encourage players to spend money to gain advancement in games (Zendle et al., 2020; Zendle, Ballou, \& Meyer, 2019a) through a process sometimes termed "predatory monetization" (King \& Delfabbro, 2018b). A particular kind of online microtransaction is a "loot box"; a mystery item that, once purchased, will reveal its values or set of values (Drummond et al., 2020a, b; Griffiths, 2018). Since their arrival, loot boxes have been under scrutiny, with particular attention directed towards their similarity to gambling (Drummond et al., 2019; King \& Delfabbro, 2019b, 2020). Not only do loot boxes facilitate rewards on a variable ratio reinforcement schedule; many meet Griffiths' (1995) five criteria that differentiate gambling from other risk-taking activities.

Due to these conceptual similarities, concerns have been raised as to whether loot boxes may increase the harm associated with gambling and also be a risk factor for more vulnerable gamers. In line with this view, King and Delfabbro (2018a, b) highlighted examples of microtransactions as "predatory" and capable of leading to forms of entrapment and excessive expenditure (Brocker et al., 1979; Rubin \& Brockner, 1975). Studies of adolescents have shown that loot box engagement is positively correlated with problem gambling severity. Adolescent consumers engaging with loot boxes are more likely to be classified as a problem gambler than non-engaging peers, and adolescent problem gamblers spend more on loot boxes than non-problem gambler peers (Kristiansen \& Severin, 2020; Zendle, Meyer, \& Over, 2019b). Such results also emerge in adult studies, with Zendle and Cairns (2018, 2019) showing that loot box expenditure was significantly linked to problem gambling severity and that there was a significant difference in loot box expenditure between problem gamblers and low-risk and/or moderate-risk gamblers. Studies have also demonstrated significant associations between loot box expenditure and problem gambling severity, excessive/ problem video gaming, and psychological distress (Drummond, Sauer, Ferguson, \& Hall, 2020a; Li et al., 2019). These results may indicate that loot boxes are attractive features for people already involved with gambling (see Delfabbro \& King, 2020) and raise questions about whether the products of loot boxes (e.g. skins) might be used as a currency to gamble on online sites that all these game assets to be used as a form of currency. Little research has examined whether the existence of these new features may potentially contribute to harmful consequences.

\section{The Present Study}

There is currently no literature assessing for graded harm in regular gamers and those reporting problem gaming (i.e. meeting IGD criteria). Further, little is known about whether newer features of games, such as loot boxes, are increasing the harms (particularly the financial ones) associated with excessive gaming. For these reasons, the aim of the present study was to survey for harm in regular gamers and specifically test the relationship between (a) IGD status and harm and (b) loot box expenditure and financial harm. Items from Browne et al.'s (2016) taxonomy of gambling harms were adapted to gaming and administered using a method developed by Blaszczynski et al. (2015) and applied by Delfabbro, Georgiou, and King (2020a). This method requires respondents to endorse harms but also rate the extent to which any endorsed harm was attributable to gaming. It was hypothesised that problem gamers would score higher on the different measures of gaming-related harm and that loot box expenditure would be positively associated with the level of financial harm reported. The 
study also examined whether meeting the IGD cut-off would be associated with harm after controlling for a range of other variables (e.g. problem gambling severity, overall psychological distress) that the literature has (a) identified as known correlates of IGD and (b) are potential factors related to harm.

\section{Method}

The study was approved by the Human Research Ethics Subcommittee in the School of Psychology at the University of Adelaide (Approval 20/08).

\section{Participants}

The final sample comprised 471 adult regular gamers recruited from an online panel provider (Prolific). Participants were required to play games at least 3 days in a typical week and to be over 18 years of age. A total of 215 participants resided in mainland Europe (45.6\%); 147 resided in North America (31.2\%); 65 resided in the UK or Ireland (13.8\%); 25 resided in Australia or New Zealand (5.3\%); and the remaining 19 participants resided in either Asia, Africa, or South America (4.0\%). A total of 380 participants identified as male (80.7\%), 73 as female $(15.5 \%)$, and 18 as neither (3.8\%). Full demographic characteristics can be found in Table 1, with separate groupings for IGD status.

As shown in Table 1, the sample was predominantly male (80\%) and aged 18-30 years (80\%). The sample included people with a mixture of relationship, employment, and living arrangements. The sample generally reported a low prevalence of health-related behaviours such as smoking and other substance use. Around one-third appeared to be living in financially precarious circumstances. Chi-square tests revealed no significant demographic and lifestyle differences between IGD statuses.

\section{Procedure}

The study, advertised as The Benefits and Harms of Gaming, was made available on Prolific on two occasions in March and May of 2020. On both occasions, the active participant load allowed (350 and 150, respectively) was filled within twenty minutes. Once accepting a place, participants were presented with an online consent form with researcher contact information. The survey took on average 24 min to complete, and participants were paid for their time via Prolific.

\section{Measures}

Demographics Participants indicated their gender, age range, work status, living status, and financial vulnerability (based on whether they could raise the equivalent of US\$2000 in an emergency).

Gaming Behaviour Participants were asked to indicate their favourite gaming genre; their gaming platform of choice (e.g. desktop computer, home gaming console); their gaming days per week; and the hours per day. Participants who indicated they gamed less than 3 days per week, contradicting selection criteria, were excluded from the survey. Participants were then asked how many times in the past three months they had spent money on gaming in general; 
Table 1 Demographic characteristics of groups classified by IGD status $(\mathrm{N}=471)$

\begin{tabular}{|c|c|c|c|c|}
\hline Variable & $\begin{array}{l}\text { Overall } \\
(\mathrm{N}=471) \\
\mathrm{N}(\%)\end{array}$ & $\begin{array}{l}\text { IGD } \\
(N=84) \\
\mathrm{N}(\%)\end{array}$ & $\begin{array}{l}\text { No IGD } \\
(N=387) \\
\mathrm{N}(\%)\end{array}$ & $\chi^{2}$ \\
\hline \multicolumn{5}{|l|}{ Gender } \\
\hline Male & $380(80.7)$ & $65(77.4)$ & $315(81.4)$ & \\
\hline Female & $73(15.5)$ & $14(16.7)$ & $59(15.2)$ & \\
\hline Other & $18(3.8)$ & $5(6.0)$ & $13(3.4)$ & Ns \\
\hline \multicolumn{5}{|l|}{ Age } \\
\hline $18-30$ & $375(79.6)$ & $70(83.3)$ & $305(78.8)$ & \\
\hline $31-40$ & $73(15.5)$ & $11(13.1)$ & $62(16.0)$ & \\
\hline $41-50$ & $16(3.4)$ & $2(2.4)$ & $14(3.6)$ & \\
\hline $51-60$ & $3(0.6)$ & $0(0.0)$ & $3(0.8)$ & \\
\hline $61+$ & $4(0.8)$ & $1(1.2)$ & $3(0.8)$ & Ns \\
\hline \multicolumn{5}{|l|}{ Employment } \\
\hline Full-time & $162(34.4)$ & $25(29.8)$ & $137(35.4)$ & \\
\hline Part-time & $52(11.0)$ & $10(11.9)$ & $42(10.9)$ & \\
\hline Student & $141(29.9)$ & $25(29.8)$ & $116(30.0)$ & \\
\hline Other & $116(24.6)$ & $24(28.6)$ & $92(23.8)$ & Ns \\
\hline \multicolumn{5}{|l|}{ Relationship status } \\
\hline Single & $270(57.3)$ & $42(50.0)$ & $228(58.9)$ & \\
\hline In relationship/married & $196(41.6)$ & $41(48.8)$ & $155(40.1)$ & \\
\hline Divorced/separated & $5(1.1)$ & $1(1.2)$ & $4(1.0)$ & Ns \\
\hline \multicolumn{5}{|l|}{ Living situation } \\
\hline With parents & $267(56.7)$ & $49(58.3)$ & $218(56.3)$ & \\
\hline Renting & $124(26.3)$ & $23(27.4)$ & $101(26.1)$ & \\
\hline Owning and occupying & $80(17.0)$ & $12(14.3)$ & $68(17.6)$ & Ns \\
\hline \multicolumn{5}{|l|}{ Raising US\$2000 in emergency } \\
\hline Easily & $128(27.2)$ & $20(23.8)$ & $108(27.9)$ & \\
\hline With sacrifices & $177(37.6)$ & $27(32.1)$ & $150(38.8)$ & \\
\hline Drastic measures & $113(24.0)$ & $27(32.1)$ & $86(22.2)$ & \\
\hline Unable to do it & $53(11.3)$ & $10(11.9)$ & $43(11.1)$ & Ns \\
\hline \multicolumn{5}{|l|}{ Health behaviour } \\
\hline Smokes (weekly or more) & $54(11.5)$ & $8(9.5)$ & $46(11.9)$ & Ns \\
\hline Vapes (weekly or more) & $52(11.0)$ & $12(14.3)$ & $40(10.3)$ & Ns \\
\hline Recreational drugs (weekly or more) & $27(5.7)$ & $4(4.8)$ & $23(5.9)$ & Ns \\
\hline Gambling (weekly or more) & $60(12.7)$ & $14(16.7)$ & $46(11.9)$ & Ns \\
\hline
\end{tabular}

Note. Participants were classified as IGD if meeting IGD criteria as per Petry et al.'s (2014) measure. Participants were classified as No IGD if not meeting these criteria. $\chi^{2}=p$ value of a chi-square test of independence. Ns $=$ not significant, $p>.05$

gaming software; loot boxes; and other microtransactions. Following this, after selecting the currency of their choice, participants reported how much they spent on each occasion within the previous four domains.

Other Health-Related Behaviours Participants indicated how often they engaged in other health-related behaviours. They were asked how many caffeinated drinks they consumed in a typical gaming session, how often they currently smoked cigarettes or vaped e-cigarettes, and how often they used recreational drugs such as marijuana.

Gaming Benefits Participants completed the 10-item Benefits of Gaming scale adapted from a similar gambling-related scale developed by Delfabbro, Georgiou, and King (2020a). Each item had a 5 -point response scale, where $1=$ strongly disagree, $2=$ disagree, $3=$ neutral, $4=$ 
agree, and $5=$ strongly agree. Higher scores indicated that the person derived greater benefits from gambling. To adapt from the Delfabbro, Georgiou, and King (2020a) measure, each instance of the world "gambling" was replaced with the word "gaming". Cronbach's alpha for this measure was 0.70 .

Internet Gaming Disorder This study used Petry et al.'s (2014) 9-item DSM-5-derived diagnostic measure to screen for possible IGD. Participants were asked to endorse or refute each item. Scores of 4 or below indicate non-problematic gaming, whereas scores of 5 or above indicate symptoms consistent with IGD. The checklist has been used in clinical and neurobiological studies of IGD and shown strong psychometric qualities (King et al., 2020a, b). In this sample, 84 participants (17.8\%) endorsed five or more items, consistent with IGD. The KR-20 coefficient was 0.65 .

Problem Gambling Participants completed the Problem Gambling Severity Index (PGSI) (Ferris \& Wynne, 2001). Each item had a 4-point response scale, where $0=$ never, $1=$ sometimes, $2=$ most of the time, and $3=$ almost always. The PGSI has a 12-month time frame. Scores of 0 indicate recreational gambling or non-participation, 1 to 2 indicate low risk gambling, 3 to 7 moderate risk gambling, and scores of 8 to a maximum 27 indicate problem gambling. This sample contained 12 problem gamblers (3.5\%), 21 moderate-risk gamblers (4.4\%), 59 low-risk gamblers (12.5\%), and 379 recreational gamblers or gambling nonparticipants $(80.3 \%)$. Cronbach's alpha for this scale was 0.89 .

Psychological Distress Participants completed the Kessler 10 (K10) (Kessler et al., 2003) which is a 10-item questionnaire reflecting the symptomatic frequency of depression, anxiety, and stress experienced in the previous 4 weeks. Each item has a 5-point rating scale, where $1=$ never, $2=$ a little of the time, $3=$ some of the time, $4=$ most of the time, and $5=$ all of the time. Higher scores indicate greater distress. Cronbach's alpha for this measure was 0.92 .

Gaming Harm To assess gaming-related harm, this study used the gambling-related harm questionnaire developed by Browne et al. (2016) and scored using the method applied in Delfabbro, Georgiou, and King (2020a). Harm items are divided into six categories, with each category ranging from mild to the most severe harm: financial (reduced savings due to gambling — becoming bankrupt); work/study (being late for work-losing a job); psychological (regret—suicide attempts); social (spending less time with important people — relationship separations); and other (mostly deviant behaviours, such as crime and stealing money). Items were adapted to reflect gaming-related harm - any mention of the word "gambling" was simply replaced with "gaming". Particularly extreme items (e.g. suicide, bankruptcy) were eliminated from the survey due to its online administration.

Each harm item was first presented without reference to gaming (e.g. "In the last 12 months, feelings of regret have been...") with a 5-point rating scale $(0=$ not a problem, $1=$ a minor problem, $2=$ a moderate problem, $3=$ a major problem, and $4=$ a very serious problem). Any participant giving a response of 1 or more was given a follow-up item, asking for their attribution of harm to gaming (e.g. "My feelings of regret were...") with another 5point scale $(0=$ not caused by my gaming, $1=$ slightly caused by gaming, $2=$ moderately caused by my gaming, $3=$ mostly caused by my gaming, and $4=$ totally caused by my gaming). The final harm measure was 57 items in length, with 13 financial items, 11 health items, 10 psychological items, 9 social items, 7 work and study items, and 7 other items. 
Validity Checks Participants answered two simple questions to ensure they were not responding invalidly. The first question asked them to select the former US president from the options of Donald Trump, Joe Biden, Barack Obama, and Vladimir Putin. The second question asked them to select the odd number from a list of otherwise even numbers. While two participants did not correctly identify Barack Obama as a former US president, they both remained in the sample due to their (a) otherwise consistent responding and (b) residence outside of the USA.

\section{Data Preparation}

While 540 participants began the study, 4 were disqualified for completing the study too quickly; 15 were disqualified for gaming less than 3 days per week; and 12 surveys were left incomplete. Of the 509 remaining, a further 38 were eliminated because of unrealistic, aberrant, or inconsistent responding. For example, 11 participants were removed for endorsing gaming more than $84 \mathrm{~h}$ of gaming time per week (i.e. more than $12 \mathrm{~h}$ every day), as this figure was considered too extreme to be reliable. Other validity checks were based on crosstabulations to identify illogical responses (e.g. participants were excluded for endorsing experiences of "extreme distress" in the past 12 months, but not subsequently endorsing any experiences of "distress"). Participants were also excluded for meeting PGSI criteria for problem gambling, but not endorsing participating in any gambling activities during the PGSI's time frame of reference (the last 12 months).

\section{Data Analysis}

In line with STROBE guidelines, all data was inspected to identify any extreme outliers (+2SD) using scatter plot and frequency distributions inspections. We did not find any significant outliers likely to cause problems with the analysis and this was confirmed using sensitivity analyses that tested principal relationships with, and without, the top $2 \%$ of values. A number of variables showed natural variations from normality (i.e. most people score lower on measures of gaming disorder), but we found no evidence of discontinuity, bimodality, or extreme outliers that would compromise analyses. Spearman and Pearson correlation analyses, for example, produced very similar results.

Harms were scored in three ways using the method employed by Delfabbro, Georgiou, and King (2020a) and developed originally by Blaszczynski et al. (2015). A person was considered to have endorsed "general harm" if they scored 1 or more on the first question of any item (i.e. indicating "A minor problem" or more). If these participants then gave a score of 1 or more on the second question (i.e. attributing it to being "Slightly caused by my gaming" or more), they were considered to have reported this harm for gaming. Any item endorsed in this way was labelled "any harm" due to gaming. The final category of harm ("moderate harm") required that participants give a score of 2 or more on the first question of any item (i.e. "A moderate problem" or more), and give a score of 2 or more on the follow-up question (i.e. attributing it to being "Moderately caused by my gaming" or more). Using these methods, it was possible to add up the total number of items indicating: "general harm", not necessarily connected to gaming; "any harm" due to gaming; or, any "moderate harm" due to gaming. A power analysis indicated that the sample size was sufficient to detect small effect sizes (correlations or mean differences) with $\alpha=0.05$ and $1-\beta=0.80$. 


\section{Results}

\section{Gaming Behaviour}

Consistent with the inclusion criteria, participants reported playing between 3 and 7 days in a typical week $(M=5.91, S D=1.29)$ and hours per week ranged between 4 and $77(M=25.6$, $S D=15.7)$. A total of 45 participants played less than $10 \mathrm{~h}$ per week $(9.6 \%), 287$ played between 10 and $30 \mathrm{~h}$ per week (60.9\%), and 139 played more than $30 \mathrm{~h}$ per week (29.5\%). Four different platforms were selected as participants' platform of choice: desktop and/or laptop computers were most common (71.8\%) followed by home gaming consoles $(21.9 \%)$; mobile and/or tablet apps (5.5\%); and handheld gaming consoles $(0.8 \%)$. Twelve different gaming genres were selected as participants' favourites, with the four most popular being: firstperson shooter games $(23.6 \%)$; multiplayer online battle arena games $(18.0 \%)$; traditional role playing games (16.6\%); and massively multiplayer online role playing games $(11.0 \%)$.

Gaming expenditure in the past 3 months was converted to US dollars in four domains: amount spent on gaming in general $(M=90.2, S D=294.1)$; amount spent on gaming software $(M=40.7, S D=75.5)$; amount spent on loot boxes $(M=2.81, S D=12.0)$; and amount spent on other microtransactions $(M=9.20, S D=48.9)$. In the prior three months, 385 participants had spent money on gaming in general $(81.7 \%), 312$ had spent money on gaming software $(66.2 \%), 51$ had spent money on loot boxes (10.8\%), and 140 had spent money on non-loot box microtransactions $(29.7 \%)$.

\section{Health-Related Behaviours}

Participants were also surveyed about other recreational habits. A total of 153 reported consuming caffeine while gaming $(32.5 \%) ; 54$ reported smoking cigarettes at least weekly $(11.5 \%)$; with 41 of these smoking daily $(8.7 \%)$; and 52 reported smoking e-cigarettes at least weekly $(11.0 \%)$, with 40 of these smoking daily (8.5\%). A total of 133 reported using recreational drugs ("such as marijuana") at least once a year (28.2\%) with 27 of these using weekly $(5.7 \%)$ and 12 using daily (2.5\%). Two hundred fifty-two reported gambling at least once per year $(53.5 \%)$, and 60 reported gambling weekly or more often $(12.7 \%)$.

\section{IGD Status, Problem Gambling Severity, and Other Psychometric Measures}

The average score on the Petry et al. (2014) IGD measure was 2.98 ( $S D=1.93)$, with a minimum of 0 to a maximum of 9 (reflecting the theoretical range). A total of 84 participants scored 5 or more, indicating they met criteria for IGD (17.8\%). In comparison, the mean PGSI score was $0.66(S D=2.03)$, with a minimum of 0 and a maximum of 16 (from a theoretical range of 0 to 27). A total of 379 participants recorded a 0 (80.3\%), 59 scored in the low-risk category $(12.5 \%), 21$ were moderate-risk $(4.4 \%)$, and 12 scored in the problem gambler range (3.5\%).

The average score on the Kessler 10 was $21.2(S D=8.69)$, with a minimum of 10 to a maximum of 49 (from a theoretical range of 10 to 50). A total of 145 participants were in the low range of psychological distress $(30.8 \%), 145$ were in the moderate range (30.8\%), 88 were in the high range (18.7\%), and 93 were in the very high range $(19.7 \%)$. 


\section{Harm Measures}

Table 2 summarizes the total harm items endorsed by participants who did or did not meet the IGD criteria, and for the sample as a whole. The maximum possible score for each of the 3 scoring methods was 57. As indicated, those with IGD scored significantly higher on all three counts with large effects.

Table 3 displays the domain-specific harm totals based on IGD classification. These analyses indicated that IGD-positive gamers reported more harm than IGD-negative gamers in every harm category, and irrespective of how harm was scored. These differences are shown in Fig. 1 to provide a clearer graphical illustration.

\section{Association Between Loot Box Expenditure and Financial Harm}

A total of 51 participants reported spending money on loot boxes in the past 3 months $(10.8 \%)$. Of the participants reporting loot box expenditure, loot boxes were engaged an average of 2.10 times in the past 3 months $(S D=2.21)$, with an average of US $\$ 16.49$ spent on each occasion $(S D=18.26)$. When extrapolated, these participants spent an average of US $\$ 25.97$ ( $S D=$ 27.24) on loot boxes in the past 3 months. The highest recorded loot box expenditure over the past 3 months was by a participant who reported spending US\$133.20.

Table 4 summarizes the association between participants' loot box expenditure and their reports of general harm, any harm, and moderate harm on the thirteen financial items. Pearson's $r$ correlations revealed significant positive associations between loot box expenditure and all three harm variables. Pearson correlations indicated a non-significant positive association between the sample's loot box expenditure and reports of general financial harm, and significant but small positive correlations for harms scored using the other two methods. These findings were consistent with the hypothesised associations.

\section{Predictors of General Harm, Any Gaming Harm, and Moderate Gaming Harm}

Table 5 summarizes the results of Pearson correlation analyses examining the bivariate relationships between a variety of survey variables and the three harm categories. A number of variables were not significantly related to harm scores. These included all forms of non-loot box gaming expenditure; perceived benefits of gaming; vaping frequency; and recreational drug use frequency. Conversely, smoking frequency and financial vulnerability (i.e. reported difficulty in raising US\$2000 in an emergency) had a weak positive association with general harm. Age was significantly negatively associated with general harm, with harm counts smaller in older participants (albeit weakly). As previously discussed, loot box expenditure

Table 2 Total harm counts by IGD status $(\mathrm{N}=471)$

\begin{tabular}{|c|c|c|c|c|c|c|}
\hline Category & $\begin{array}{l}\text { Overall } \\
\text { M (SD) }\end{array}$ & $\begin{array}{l}\text { IGD } \\
(n=84) \\
M(S D)\end{array}$ & $\begin{array}{l}\text { No IGD } \\
(\mathrm{n}=387) \\
\mathrm{M}(\mathrm{SD})\end{array}$ & $t(469)$ & $p$ & $\mathrm{~d}$ \\
\hline General harm & $14.9(7.54)$ & $20.7(8.51)$ & $13.6(6.70)$ & 8.35 & $<0.001$ & 0.93 \\
\hline Any harm & $4.48(5.55)$ & $10.8(8.55)$ & $3.11(3.35)$ & 13.5 & $<0.001$ & 1.18 \\
\hline Moderate harm & $1.00(2.44)$ & $3.15(4.50)$ & $0.53(1.29)$ & 9.78 & $<0.001$ & 0.79 \\
\hline
\end{tabular}

Note. $T$-score, $p$ value, and Cohen's $d$ are all in reference to independent samples $t$-tests between IGD statuses 
Table 3 M (SD) harm counts within each domain of harm by IGD status. $(\mathrm{N}=471)$

\begin{tabular}{|c|c|c|c|c|c|c|}
\hline Category & $\begin{array}{l}\text { Overall } \\
\mathrm{M}(\mathrm{SD})\end{array}$ & $\begin{array}{l}\operatorname{IGD}(\mathrm{n}=84) \\
\mathrm{M}(\mathrm{SD})\end{array}$ & $\begin{array}{l}\text { No IGD }(n=387) \\
\text { M (SD) }\end{array}$ & $t(469)$ & $p$ & $\mathrm{~d}$ \\
\hline \multicolumn{7}{|l|}{ General harm } \\
\hline Financial & $2.24(2.25)$ & $3.43(3.02)$ & 1.99 (1.96) & 5.48 & $<0.001$ & 0.57 \\
\hline Health & $4.05(2.19)$ & $5.38(2.31)$ & $3.75(2.06)$ & 6.42 & $<0.001$ & 0.74 \\
\hline Psychological & $6.13(2.84)$ & $7.82(2.16)$ & $5.77(2.84)$ & 6.24 & $<0.001$ & 0.81 \\
\hline Social & $2.29(2.17)$ & $3.52(2.55)$ & $2.02(1.98)$ & 5.97 & $<0.001$ & 0.66 \\
\hline Work and Study & 1.48 (1.59) & $2.33(1.89)$ & $1.29(1.45)$ & 5.63 & $<0.001$ & 0.62 \\
\hline Other & $0.19(0.64)$ & $0.57(1.21)$ & $0.11(0.39)$ & 6.24 & $<0.001$ & 0.51 \\
\hline \multicolumn{7}{|l|}{ Any harm } \\
\hline Financial & $0.61(1.37)$ & $1.46(2.36)$ & $0.42(0.94)$ & 6.64 & $<0.001$ & 0.58 \\
\hline Health & $1.45(1.77)$ & $3.35(2.44)$ & $1.03(1.27)$ & 12.5 & $<0.001$ & 1.19 \\
\hline Psychological & 1.59 (2.09) & $3.71(2.73)$ & $1.13(1.59)$ & 11.6 & $<0.001$ & 1.15 \\
\hline Social & $0.77(1.45)$ & $2.00(2.26)$ & $0.50(1.03)$ & 9.34 & $<0.001$ & 0.85 \\
\hline Work and Study & $0.80(1.33)$ & $1.68(1.82)$ & $0.61(1.12)$ & 6.99 & $<0.001$ & 0.71 \\
\hline Other & $0.07(0.43)$ & $0.25(0.90)$ & $0.03(0.20)$ & 4.32 & $<0.001$ & 0.34 \\
\hline \multicolumn{7}{|l|}{ Moderate harm } \\
\hline Financial & $0.10(0.45)$ & $0.25(0.78)$ & $0.06(0.33)$ & 3.49 & $<0.001$ & 0.31 \\
\hline Health & $0.41(0.98)$ & $1.31(1.71)$ & $0.22(0.56)$ & 10.3 & $<0.001$ & 0.86 \\
\hline Psychological & $0.30(0.97)$ & $0.95(1.80)$ & $0.16(0.57)$ & 7.22 & $<0.001$ & 0.59 \\
\hline Social & $0.18(0.70)$ & $0.63(1.32)$ & $0.09(0.42)$ & 6.70 & $<0.001$ & 0.55 \\
\hline Work and Study & $0.25(0.74)$ & $0.65(1.14)$ & $0.16(0.59)$ & 5.71 & $<0.001$ & 0.54 \\
\hline Other & $0.01(0.09)$ & $0.01(0.11)$ & $0.01(0.09)$ & 0.38 & 0.71 & 0 \\
\hline
\end{tabular}

Note. T-score, $p$ value, and Cohen's $d$ all reference independent samples $t$-tests

was not found to be associated with general harm, but was positively associated with any and moderate harm.

As indicated in Table 5, gaming hours per week and caffeine consumption were found to have small significant positive associations with all three harm scoring categories. K10 scores were related to harm scores across all three scoring categories. PGSI scores were positively associated with General, Any, and Moderate categories, with the strongest relationships

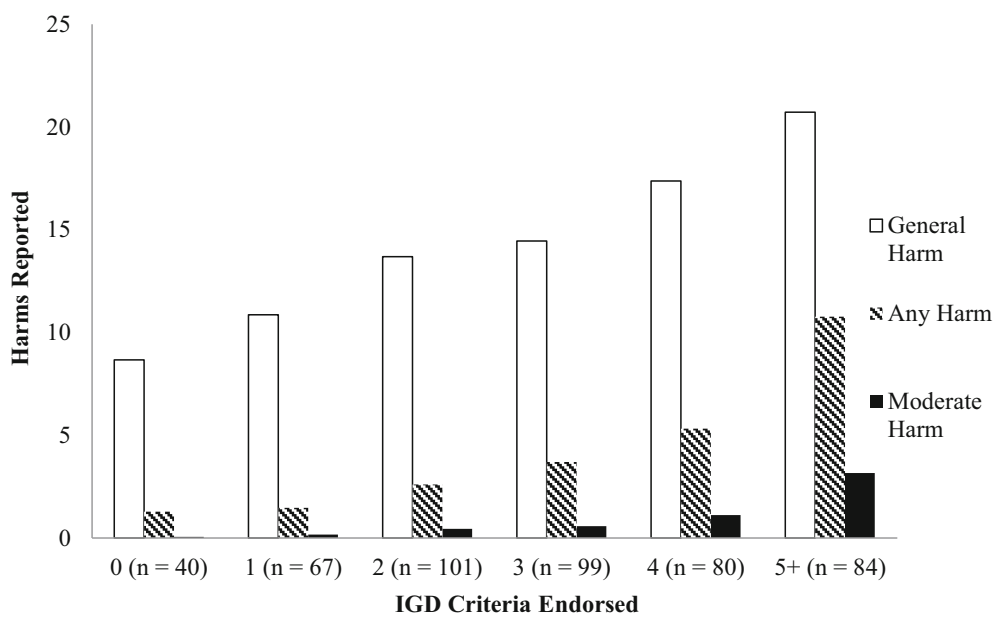

Fig. 1 Number of Internet gaming disorder (IGD) criteria endorsed through the Petry et al. (2014) measure, versus general, any, and moderate harm reported. $(N=471)$ 
Table 4 Pearson correlations between loot box expenditure and financial harm

\begin{tabular}{llll}
\hline Measure & 1 & 2 & 3 \\
\hline 1. Loot box expenditure & & & \\
2. General harm, financial & 0.02 & $0.51 * * *$ & $0.51 * * *$ \\
3. Any harm, financial & $0.14^{* *}$ & $0.21^{* * *}$ & $0.51^{* * *}$ \\
4. Moderate harm, financial & 0.26 .
\end{tabular}

Note. Loot box expenditure pertained to spending activity in the past 3 months. Participants reported a value in the currency of their choice, with conversion to US dollars performed by the researchers using Table CC. ** $p<.01, * * * p<.001$

observed for the harm associated with gaming (any and moderate harm counts). Overall, the strongest predictor in all three harm categories was the number of IGD criteria met (i.e. the score on the Petry et al., 2014 measure).

Multiple Regression Multiple regression analysis was used to investigate the best predictors of moderate harm, using variables presenting a significant bivariate association with moderate harm (see Table 5 ). The results indicated that the model significantly predicted moderate harm scores $\left(F(7,463)=26.1, p<0.001, R^{2}=0.31\right)$. Significant predictors in the model were: IGD criteria endorsed $(B=0.48, p<0.001)$; gaming hours per week $(B=0.02, p<0.001)$; loot box expenditure $(B=0.02, p<0.01)$; PGSI score $(B=0.27, p<0.001)$; and perceived benefits of gaming $(B=-0.07, p<0.01)$. Non-significant variables were: caffeine consumption during gaming $(B=0.01, p=0.10)$; and $\mathrm{K} 10$ score $(B=-0.01, p=0.43)$.

An updated multiple regression discarded the non-significant variables. This model also explained a significant proportion of the variance in moderate harm scores $(F(5,465)=40.9$, $\left.p<0.001, R^{2}=0.31\right)$. All variables remained significant predictors of harm score: IGD criteria endorsed $(B=0.47, p<0.001)$; gaming hours per week $(B=0.02, p<0.001)$; loot box expenditure $(B=0.02, p<0.01)$; PGSI score $(B=0.27, p<0.001)$; and perceived benefits of gaming $(B=-0.07, p<0.01)$.

Table 5 Pearson correlations between survey variables and harm counts

\begin{tabular}{llll}
\hline Measure & General harm & Any harm & Moderate harm \\
\hline IGD criteria endorsed & $0.47^{* * *}$ & $0.59^{* * *}$ & $0.46^{* * *}$ \\
Gaming hours per week & $0.15^{* *}$ & $0.18^{* * *}$ & $0.21^{* * *}$ \\
Expenditure, loot boxes & 0.02 & $0.17^{* * *}$ & $0.20^{* * *}$ \\
Expenditure, other microtransactions & 0.05 & 0.05 & 0.04 \\
Expenditure, gaming software & 0.05 & 0.08 & 0.05 \\
Expenditure, gaming in general & 0.05 & 0.03 & 0.01 \\
Financial vulnerability & $0.26^{* * *}$ & 0.03 & 0.05 \\
K10 & $0.44^{* * *}$ & $0.18^{* * *}$ & $0.14 * *$ \\
PGSI & $0.20^{* * *}$ & $0.42^{* * *}$ & $0.35^{* * *}$ \\
Benefits of gaming & -0.01 & -0.01 & -0.04 \\
Age range & $-0.11 *$ & -0.09 & -0.06 \\
Caffeine consumption & $0.10^{*}$ & $0.15^{* *}$ & $0.13^{* *}$ \\
Smoking frequency & $0.14 * *$ & 0.02 & 0.03 \\
Vaping frequency & -0.01 & 0.00 & 0.01 \\
Drug use frequency & 0.08 & 0.03 & 0.00 \\
\hline
\end{tabular}

Notes. $* p<0.05, * * p<0.01, * * * p<0.001$ 


\section{Discussion}

\section{Gaming and Harm}

The present study aimed to examine the extent to which gamers classified as having IGD differed from other gamers on a range of harm dimensions. The study also investigated whether new features, such as loot boxes, were associated with greater harm: in particular, financial harm. The results were generally as hypothesised. Gamers who met criteria for IGD reported more harm than regular gamers who did not meet the criteria. Differences were observed across all harm dimensions, irrespective of whether the harms were considered "slightly" or "moderately" related to gaming. The results also showed that loot box expenditure was associated with greater gaming-related financial harm. The results further showed that IGD symptoms were positively related to harm after controlling for other co-morbidities (e.g. scores on the PGSI) and other lifestyle factors. However, some of these factors were significant in their own right. For example, harm scores were positively related to how many hours of gaming were undertaken each week; overall levels of psychological distress (K10 scores); problem gambling severity (PGSI scores); and the level of reported caffeine consumption. IGD was also predicted by the amount of loot box expenditure per month. On the other hand, and logically consistent with this pattern of results, those who reported obtaining greater benefits from gaming generally reported lower levels of harm.

Overall, these findings confirm, using a systematic taxonomy of harms, many of the findings from previous studies. However, an important feature of this study was the use of questions that required respondents to attribute the harms to gaming. Consistent with previous studies (e.g. Männikkö et al., 2015; Satghare et al., 2016; Tetik et al., 2018), the most common form of harm in IGD related to physical health (e.g. items related to poor diet, sleep, hygiene). For this category, the count of moderately scored harm was six times higher for those with IGD than those without. The next most commonly endorsed form of harm was psychological with IGD-classified individuals reporting problems such as distress, anxiety, or depression six times more commonly than non-IGD participants. This was consistent with some past studies (Cheng et al., 2018; Gonález-Bueso et al., 2018; Kim et al., 2016; Wu et al., 2015). We also observed that higher scores on the PGSI were associated with greater gaming harm, consistent with other studies that have observed evidence of cross-addiction (e.g. Burleigh et al., 2019; Spekman et al., 2013). Disruptions to work and study were generally rarer, but much more likely to be reported by IGDclassified individuals, consistent with past studies (Northrup \& Shumway, 2014).

\section{Risk Factors for Gaming Harm}

On the other hand, despite concerns about the potentially increasing financial risks of gambling, we found that expenditure on loot boxes was generally low. Nevertheless, in support of the findings of other studies (e.g. Kristiansen \& Severin, 2020; Zendle \& Cairns, 2018, 2019; Zendle, Meyer, \& Over, 2019b), we observed that loot box expenditure was associated with greater gaming-related harm. We believe that this effect probably results from the fact that gamers who have higher levels of gaming involvement or commitment are more likely to use loot boxes. Higher involvement very likely acts as a common antecedent to both greater loot box use and harm. This observation is consistent with studies in gambling (e.g. Delfabbro, King, et al., 2020b; Hing et al., 2018) which note that problem gamblers (or higher frequency gamblers) tend to engage in a wider range of, and often in more "exotic", gambling 
activities. Further analysis of populations of gamers with greater involvement in loot box playing would be needed to determine whether this result is merely an outcome of the nature of the sample used in the present study.

\section{Limitations}

There are several limitations that need to be taken into account. First, this study was based on a self-report methodology and used an online panel, so it is unclear whether the findings can be generalized to all gamer populations. Second, the study focused on adults and did not capture the experiences of adolescents who are also engaged in high levels of gaming. Third, it may be that adapting harm items from the gambling field omitted some gaming-specific harms (such as vision problems, or neck and back aches) that are specific to excessive screen time. Fourth, the study, for ethical reasons, omitted items relating to suicidality or self-harm, so it is not clear if a small number of gamers might have endorsed those items. Fifth, we recognize that our sampling strategy might not have targeted those gamers who are most likely to spend money on loot boxes. Use of a specific mobile gaming population, rather than our general gamer population sample, may have yielded stronger insights into the links between loot boxes and financial harm. Sixth, the study employed a cross-sectional design so it is not possible to ascertain whether there is a causal relationship between gaming and harm. Seventh, in almost any harm research involving screening measures, it is important to acknowledge that it is difficult to avoid some element of circularity. Measures such the Petry IGD measure and the PGSI contain harm items, and so this increases the likelihood of people who are classified as having the disorders scoring higher on other measures of harm. Finally, given that the study was conducted early in the COVID-19 pandemic, some of the harms reported could have been due to pandemic-related health, economic, and occupational conditions.

\section{Conclusion}

The results of this study show that regular gamers who met the criteria for IGD were significantly more likely to report harm than other gamers across all measured harm dimensions. Loot box expenditure was also related to greater endorsement of gaming-related financial harm. These findings provide further evidence of the convergent validity of the Petry et al. (2014) IGD criteria. These findings encourage the need for further development of gaming-specific measures of harm, as well more detailed analysis of harm severity. Although the IGD classification used in this study appears to identify people with clearly more negative experiences of gaming, this does not mean that these harms are necessarily as severe as those observed for other conditions (such as disordered gambling).

Funding This narrative review did not require any funding support.

\section{Declarations}

Ethical Approval All procedures performed in studies involving human participants were in accordance with the ethical standards of the institutional and/or national research committee and with the 1964 Helsinki declaration and its later amendments or comparable ethical standards. 


\section{Conflict of Interest}

Patrick Carey.

I have no conflicts of interest to declare.

Paul Delfabbro.

I have received funding for research, support for conference travel and speaking engagements from government and non-government research bodies such as AGRI, VRGF, IAGR and the Department of Consumer Affairs, GambleAware/RGT, Gambling Research Australia, Independent Gambling Authority, the ARC, NHMRC, Channel 7 Children's Foundation, and Australian Institute of Criminology. I have conducted paid consultancy work on responsible gambling for regulatory bodies, government, peak bodies such as the Australasian Gambling Commission and reviews of responsible gambling programs for some industry groups (e.g. reviews of list of indicators, self-exclusion program, host responsibility quality in relation to international best practice), but not received direct industry funding for any research. I acknowledge that many peak research bodies are indirectly funded by industry through levies or contributions.

Dr. Daniel King.

I have received funding support for conference travel, research and speaking engagements from government and non-government organizations including the Victorian Responsible Gambling Foundation, Gambling Research Australia, NSW Department of Customer Service, WHO, and ARC. I have not undertaken any research funded by industry.

\section{References}

American Psychiatric Association. (2013). Diagnostic and statistical manual of mental disorders (Fifth ed.). American Psychiatric Association.

Blaszczynski, A., Anjoul, F., Shannon, K., Keen, B., Pickering, D., \& Wieczorek, M. (2015). Gambling harm minimisation report. Office of Liquor, Gambling and Racing, NSW.

Brocker, J., Shaw, M. C., \& Rubin, J. Z. (1979). Factors affecting withdrawal from an escalating conflict: quitting before it's too late. Journal of Experimental Social Psychology, 15, 492-503. https://doi.org/10.1016/00221031(79)90011-8.

Browne, M., \& Rockloff, M. (2018). Prevalence of gambling-related harm provides evidence for the prevention paradox. Journal of Behavioral Addictions, 7, 410-422. https://doi.org/10.1556/2006.7.2018.41.

Browne, M., Langham, E., Rawat, V., Greer, N., Li, E., Rose, J., Rockloff, M., Donaldson, P., Thorne, H., Goodwin, B., Bryden, G., \& Best, T. (2016). Assessing gambling-related harm in Victoria: a public health perspective. Victorian Responsible Gambling Foundation.

Burleigh, T. L., Griffiths, M. D., Sumich, A., Stavropoulos, V., \& Kuss, D. J. (2019). Systematic review of the co-occurrence of gaming disorder and other potentially addictive behaviors. Current Addiction Reports, 6 , 383-401. https://doi.org/10.1007/s40429-019-00279-7.

Cheng, Y. S., Tseng, P. T., Lin, P. Y., Chen, T. Y., Stubbs, B., Carvalho, A. F., Wu, C. K., Chen, Y. W., \& Wu, M. K. (2018). Internet addiction and its relationship with suicidal behaviors: a meta-analysis of multinational observational studies. The Journal of Clinical Psychiatry, 79(4), 17r11761. https://doi.org/10.4088/jcp. $17 \mathrm{r} 11761$.

Delfabbro, P. H., \& King, D. L. (2020). Gaming-gambling convergence: evaluating evidence for the 'gateway' hypothesis. International Gambling Studies, 20, 380-392. https://doi.org/10.1080/14459795.2020.1768430.

Delfabbro, P., Georgiou, N., \& King, D. (2020a). Measuring gambling harm: The influence of response scaling on estimates on estimates and the distribution of harm across PGSI categories. Journal of Gambling Studies, Advanced online publication. https://doi.org/10.1007/s10899-020-00954-1.

Delfabbro, P., King, D., Browne, M., \& Dowling, N. (2020b, in press). Do EGMs have the strongest association with problem gambling than racing and casino table games?: evidence from a decade of Australian prevalence studies. Journal of Gambling Studies, 36(2), 499-511. https://doi.org/10.1007/s10899-02009950-5.

Drummond, A., Sauer, J. D., \& Hall, L. C. (2019). Loot box limit-setting: a potential policy to protect video game users with gambling problems? Addiction, 114, 935-936. https://doi.org/10.1111/add.14583.

Drummond, A., Sauer, J. D., Ferguson, C. J., \& Hall, L. C. (2020a). The relationship between problem gambling, excessive gaming, psychological distress and spending on loot boxes in Aotearoa New Zealand, Australian, and the United States: a cross-national survey. PLoS One, 15(3), e0230378. https://doi.org/10.1371/journal. pone. 0230378 .

Drummond, A., Sauer, J. D., Hall, L. C., Zendle, D., \& Loudon, M. R. (2020b). Why loot boxes could be regulated as gambling. Nature Human Behaviour, 4, 986-988. https://doi.org/10.1038/s41562-020-0900-3. 
Ferris, J., \& Wynne, H. (2001). The Canadian problem gambling index: final report. Submitted to Canadian Centre on Substance Abuse.

Gainsbury, S. M. (2019). Gaming-gambling convergence: Research, regulation, and reactions. Gaming Law Review, 23, 80-83. https://doi.org/10.1089/glr2.2019.2323.

Gonález-Bueso, V., Sanatamariá, J. J., Fernández, D., Merino, L., Montero, E., Jiménez-Murcia, S., del PinoGutiérrez, A., \& Ribas, J. (2018). Internet gaming disorder in adolescents: personality, psychopathology, and evaluation of a psychological intervention combined with parent psychoeducation. Frontiers in Psychology, 9, 787. https://doi.org/10.3389/fpsyg.2018.00787.

Griffiths, M. D. (1995). Adolescent gambling. Psychology Press.

Griffiths, M. D. (2018). Is the buying of loot boxes in video games a form of gambling or gaming? Gaming Law Review, 22, 52-54. https://doi.org/10.1089/glr2.2018.2216.

Hing, N., Russell, A. M. T., \& Vitartas, P. (2018). Does the uptake of wagering inducements predict impulse betting on sport? Journal of Behavioral Addictions, 7(1), 146-157. https://doi.org/10.1556/2006.7.2018.17.

International Classification of Disorders (ICD). (2019). ICD-11 for mortality and morbidity statistics. https://icd. who.int/browse11/l-m/en\#/http://id.who.int/icd/entity/1041487064

Kardefelt-Winther, D. (2014). Problematizing excessive online gaming and its psychological predictors. Computers in Human Behavior, 31, 118-122. https://doi.org/10.1016/j.chb.2013.10.017.

Kessler, R. C., Andrews, G., Cople, L. J., Hiripi, E., Mroczek, D. K., Normand, S.-L. T., Walters, E. E., \& Zaslavsky, A. (2003). Screening for serious mental illness in the general population. Archives of General Psychiatry, 60(2), 184-189. https://doi.org/10.1001/archpsyc.60.2.184.

Kim, N. R., Hwang, S. S. H., Choi, J. S., Kim, D. J., Demetrovics, Z., Király, O., Nagygyörgy, K., Griffiths, M. D., Hyun, S. Y., Youn, H. C., \& Choi, S. W. (2016). Characteristics and psychiatric symptoms of Internet gaming disorder among adults using self-reported DSM-5 criteria. Psychiatry Investigation, 13(1), 58-66. https://doi.org/10.4306/pi.2016.13.1.58.

King, D. L., \& Delfabbro, P. H. (2018a). The concept of 'harm' in Internet gaming disorder. Journal of Behavioral Addictions, 7, 562-564. https://doi.org/10.1556/2006.7.2018.24.

King, D. L., \& Delfabbro, P. H. (2018b). Predatory monetization schemes in video game (e.g. 'loot boxes') and Internet gaming disorder. Addiction, 113(11), 1967-1969. https://doi.org/10.1111/add.14286.

King, D. L., \& Delfabbro, P. H. (2019a). Internet gaming disorder. Elsevier Academic Press. https://doi.org/10. 1016/C2016-0-04107-4.

King, D. L., \& Delfabbro, P. H. (2019b). Video game monetization (e.g., 'loot boxes'): a blueprint for practical social responsibility measures. International Journal of Mental Health and Addiction, 17, 166-179. https:// doi.org/10.1007/s11469-018-0009-3.

King, D. L., \& Delfabbro, P. H. (2020). The convergence of gambling and monetised gaming. Current Opinion in Behavioral Sciences, 31, 32-36. https://doi.org/10.1016/j.cobeha.2019.10.001.

King, D., Delfabbro, P. H., \& Griffiths, M. (2010). The convergence of gambling and digital media: implications for gambling in young people. Journal of Gambling Studies, 26, 175-187. https://doi.org/10.1007/s10899009-9153-9.

King, D. L., Delfabbro, P. H., Gainsbury, S. M., Dreier, M., Greer, N., \& Billieux, J. (2019). Unfair play? Video games as exploitative monetized services: an examination of game patents from a consumer protection perspective. Computers in Human Behavior, 101, 131-143. https://doi.org/10.1016/j.chb.2019.07.017.

King, D. L., Billieux, J., Carragher, N., \& Delfabbro, P. H. (2020a). Face validity evaluation of screening tools for gaming disorder: scope, language, and overpathologizing issues. Journal of Behavioral Addictions, 9, 113. https://doi.org/10.1556/2006.2020.00001.

King, D. L., Chamberlain, S. R., Carragher, N., Billieux, J., Stein, D., Mueller, K., Potenza, M. N., Rumpf, H.-J., Saunders, J., Starcevic, V., Demetrovics, Z., Brand, M., Lee, H. K., Spada, M., Lindenberg, K., Wu, A. M. S., Lemenager, T., Pallesen, S., Achab, S., Kyrios, M., Higuchi, S., Fineberg, N., \& Delfabbro, P. H. (2020b). Screening and assessment tools for gaming disorder: a comprehensive systematic review. Clinical Psychology Review, 77, 101831. https://doi.org/10.1016/j.cpr.2020.101831.

Kristiansen, S., \& Severin, M. C. (2020). Loot box engagement and problem gambling among adolescent gamers: findings from a national survey. Addictive Behaviors, 103, 106254. https://doi.org/10.1016/j. addbeh.2019.106254.

Li, H. W., Mills, D., \& Nower, L. (2019). The relationship of loot box purchases to problem video gaming and problem gambling. Addictive Behaviors, 97, 27-34. https://doi.org/10.1016/j.addbeh.2019.05.016.

Macey, J., \& Hamari, J. (2019). eSports, skins and loot boxes: participants, practices and problematic behaviour associated with emergent forms of gambling. New Media \& Society, 21, 20-41. https://doi.org/10.1177/ 1461444818786216.

Männikkö, N., Billieux, J., \& Kääriäinen, M. (2015). Problematic digital gaming behaviour and its relation to the psychological, social and physical health of Finnish adolescents and young adults. Journal of Behavioural Addictions, 4(4), 281-288. https://doi.org/10.1556/2006.4.2015.040. 
McCaffrey, M. (2019). The macro problem of microtransactions: the self-regulatory challenges of video game loot boxes. Business Horizons, 62, 483-495. https://doi.org/10.1016/jbushor.2019.03.001.

Northrup, J. C., \& Shumway, S. (2014). Gamer widow: a phenomological study of spouses of online video game addicts. The American Journal of Family Therapy, 42(4), 269-281. https://doi.org/10.1080/011926187. 2013.847705 .

Petry, N. M., Rehbein, F., Gentile, D. A., Lemmens, J. S., Rumpf, H. J., Mößle, Bischof, G., Tao, R., Fung, D. S. S., Borges, G., Auriacombe, M., González Ibáñez, A. G., Tam, P., \& O’Brien, C. P. (2014). An international consensus for assessing Internet gaming disorder using the new DSM-5 approach. Addiction, 109(9), 13991406. https://doi.org/10.1111/add.12457.

Przybylski, A. K., Weinstein, N., \& Murayama, K. (2016). Internet gaming disorder: investigating the clinical relevance of a new phenomenon. American Journal of Psychiatry, 174, 230-236. https://doi.org/10.1176/ appi.ajp.2016.16020224.

Rawat, V., Browne, M., Bellringer, M., Greer, N., Kolandai-Matchett, K., Rockloff, M., Langham, E., Hanley, C., Du Preez, K. P., \& Abbott, M. (2018). A tale of two countries: comparing disability weights for gambling problems in New Zealand and Australia. Quality of Life Research, 27(9), 2361-2371. https://doi.org/10. 1007/s11136-018-1882-8.

Rubin, J. Z., \& Brockner, J. (1975). Factors affecting entrapment in waiting situations: the Rosencrantz and Guildenstern effect. Journal of Personality and Social Psychology, 31, 1054-1063. https://doi.org/10.1037/ h0076937.

Satghare, P., Abdin, E., Vaingankar, J. A., Chua, B. Y., Pang, S., Picco, L., Poon, L. Y., Chong, S. A., \& Subramaniam, M. (2016). Prevalence of sleep problems among those with Internet gaming disorder in Singapore. ASEAN Journal of Psychiatry, 17(2), 1-11. https://doi.org/10.1556/2006.7.2018.16.

Spekman, M., Konijn, E. A., Roelofsma, P., \& Griffiths, M. D. (2013). Gaming addiction, definition and measurement: a large-scale empirical study. Computers in Human Behavior, 29, 2150-2155. https://doi.org/ 10.1016/j.chb.2013.05.015.

Stevens, M. W. R., Dorstyn, D., Delfabbro, P. H., \& King, D. L. (2020, revised manuscript). Global prevalence of gaming disorder: a systematic review and meta-analysis. Australian and New Zealand Journal of Psychiatry

Tetik, B. K., Kayhan, D., Sertkaya, S., \& Sandikci, K. B. (2018). Evaluation of the effects of digital play addiction on eating attitudes. Pakistan Journal of Medical Sciences, 34(2), 482-486. https://doi.org/10. 12669/pjms.342.14537.

Wölfling, K., Müller, K. W., Dreier, M., Ruckes, C., Deuster, O., Batra, A., Mann, K., Musalek, M., Schuster, A., Lemenager, T., Hanke, S., \& Beutel, M. E. (2019). Efficacy of short-term treatment of internet and computer game addiction: a randomized clinical trial. JAMA Psychiatry, 76, 1018-1025.

Wood, R. T. A. (2007). Problems with the concept of video game "addiction": some case study examples. International Journal of Mental Health and Addiction, 6, 169-178. https://doi.org/10.1007/s11469-0079118-0.

Wu, C. Y., Lee, M. B., Liao, S. C., \& Chang, L. R. (2015). Risk factors of internet addiction among Internet users: an online questionnaire survey. PLoS One, 10(10), e0137506. https://doi.org/10.1371/journal.pone. 0137506.

Zendle, D., \& Cairns, P. (2018). Video game loot boxes are linked to problem gambling: results from a largescale survey. PLoS One, 13(11), e0206767. https://doi.org/10.1371/journal.pone.0206767.

Zendle, D., \& Cairns, P. (2019). Video game loot boxes are again linked to problem gambling: results of a replication study. PLoS One, 14(3), e0213194. https://doi.org/10.1371/journal.pone.0213194.

Zendle, D., Ballou, N., \& Meyer, R. (2019a). The changing face of video game monetization: an exploration of trends in loot boxes, pay-to-win, and cosmetic microtransactions in the most-played Steam games of 20102019. Unpublished manuscript, University of York, England., 15, e232780. https://doi.org/10.1371/journal. pone.0232780.

Zendle, D., Meyer, R., \& Over, H. (2019b). Adolescents and loot boxes: links with problem gambling and motivations for purchase. Royal Society Open Science, 6(6), 190049. https://doi.org/10.1098/rsos.190049.

Zendle, D., Meyer, R., Cairns, P., Waters, S., \& Ballou, N. (2020). The prevalence of loot boxes in mobile and desktop games. Addiction. https://doi.org/10.1111/add.14973.

Publisher's Note Springer Nature remains neutral with regard to jurisdictional claims in published maps and institutional affiliations. 